\title{
Isolation and Characterization of Polyvinyl Chloride (PVC) Degrading Bacteria from Polluted Sites of Gwalior City, M.P., India
}

\author{
Mohana Yadav*†, Sushil Manderia**, Shweta Singh* and Mohd. Adil Deva** \\ *School of Studies in Microbiology, Jiwaji University, Gwalior, M.P., India \\ **School of Studies in Botany, Jiwaji University, Gwalior, M.P., India \\ $†$ Corresponding author: Mohana Yadav: yadavmohna29nov@ gmail.com
}

Nat. Env. \& Poll. Tech.

Website: www.neptjournal.com

Received: 11-03-2021

Revised: 27-04-2021

Accepted: 02-05-2021

Key Words:

Polyvinyl chloride

Degradation

Bacillus species

Micrococcus species

Enrichment culture

\begin{abstract}
Plastic is harmful to nature and this issue could be solved by its degradation. Biodegradation of plastic waste utilizing bacterial strain is an eco-friendly approach. In this study, top bacterial strains that degrade the polymeric ingredient of the polymer polyvinyl chloride (PVC) were isolated and identified using a development culture procedure. For this investigation, soil from various contaminated areas was collected, which had abundant plastic waste. The biodegradation of polyvinylchloride films was studied using a liquid culture approach for six months. A couple of bacterial organism packs were then limited to emulsifying the commonly used PVC polymer in agar media. The PVC strain showed particular degradation and was chosen for further testing because the species Bacillus and Micrococcus were considered more credible. Bacillus and Micrococcus species have both proven the biodegradability of PVC based on the mean weight decrease, which was 0.873 for Bacillus species and 0.916 for Micrococcus species after a period of around six months. The FTIR study confirmed the breaking down by demonstrating the proximity of porosity and sensitivity of bacteria-infested polythene surfaces. Bacillus has a higher degradation potential than Micrococcus in our research.
\end{abstract}

\section{INTRODUCTION}

Plastic is artificially synthesized material particularly synthesized from oil-based materials called pitches (e.g., polythene and polypropylene). Currently, the use of plastic materials across the globe has increased particularly for food packing, dress, lodging, transport, building, clinical, and meat businesses. Plastics are preferred by people since they are light in weight, strong, and almost impenetrable. Plastic usage has risen steadily over the last three decades, with an average annual growth rate of $10 \%$ (Shristi Kumar et al. 2007). Plastics thrown in landfills remain there indefinitely because it contains compounds that are non-biodegradable and unsafe. At least 14 million tons of plastic end up in the ocean every year. Plastic debris is currently the most abundant type of litter in the ocean, making up $80 \%$ of all marine debris found from surface waters to deep-sea sediments (Spear et al. 1995).

Landfilling, incineration, and mechanical and chemical recycling are the most common methods for removing plastic waste nowadays (Peng et al. 2018). Landfilling is the primary method for removing plastic waste in many countries, particularly in developing countries, due to its ease of usage and low cost. By the way, the accumulated plastic garbage has poisoned a large area of land. Although the recycling of plastic waste will reduce landfill demand and recover heat, we must also reduce the normal impacts of alternative incineration spreads, like dioxin models, carbon mono-oxide, nitrogen oxides, and other pollutants. Although mechanical recycling has become an excellent method for recycling and is used for thermoplastic waste recycling, the properties of most reused materials are completely disturbed after several cycles, and so market gauges are limited. Incineration, on the other hand, can reclaim monomers and various synthetic substances from plastic waste, but its success relies on the affordability of processes and the efficiency of catalysts (Rahimi \& Garca 2017). Currently, between $9 \%$ and $12 \%$ of global plastic waste is recycled and burned, while the remaining $79 \%$ is discarded in landfills or the ecosystem. It is proposed that new ways for recycling plastic waste should be investigated (Geyer et al. 2017, Garcia \& Robertson 2017). Despite the fact that various reviews and points of view on plastic biodegradation have been conveyed, they have largely focused on the biodegradation of a single plastic microbial variety PS (Ho et al. 2018), PE (Restrepo-Flórez et al. 2014), PUR (Cregut et al. 2013, Peng et al. 2018, Magnin et al. 2019), PP (Arutchelvi et al. 2008), and PET (Wei \& Zimmermann 2017a, Kawai et al. 2019) Thorough examination concerning the biodegradation of all plastic materials are required (Wei \& Zimmermann 2017b). 
Advancement culture procedure is utilized to isolate the ideal objective species from different kinds of creatures that have existed together in nature and are normally expected to expand the overall quantities of a particular living being by advancing development, endurance (i.e., physiological rivalry) or spatial partition from other populace individuals (Tomita et al. 2004).

The goal of this study was to isolate and depict extreme polyvinyl chloride (PVC) degrading bacteria from polluted plastic waste far away from the study sites using a technique for improving the quality of collected samples and separating them from the strong mineral agar media converged with emulsified polyvinyl chloride from that point. Similarly, the study combined the initial characterization and assessment of the certain degradation perimeter of the selected bacterial strain using several experiment methods.

\section{MATERIALS AND METHODS}

\section{Soil Sample Collection}

Soil samples with plastic waste were gathered from different waste dumping sites around Gwalior city Samples were collected in a sterile polythene pack and used to isolate bacteria that debase PVC.

\section{Polymer Sample}

The PVC film was obtained from the Gwalior plastic industry and Polyvinyl chloride resin (powder) was obtained from Supreme Pvt. Ltd. Malanpur, Industrial area, Gwalior (M.P.).

\section{Isolation of Polyvinyl Chloride (PVC) Degrading Bacterial Strains through Enrichment Methods}

Natural samples from different waste-rich plastic sites were gathered, comparably as washings of soil-made sure about plastic strips were utilized as inoculants. Every 1 to $2 \mathrm{~g}$ soil sample and $1 \mathrm{~mL}$ liquid sample was debilitated to $10 \mathrm{~mL}$ and $9 \mathrm{~mL}$ utilizing standard saline and utilized as inoculum in the 1 to $100 \mathrm{~mL}$ proportion of the MSV. The mineral salt improvement (MSV) was comparative with the late utilized by, yet sustained by a slight change in the enhancement biotin $\left(20 \mathrm{mg}\right.$ ) and $\mathrm{B} 12(10 \mathrm{mg}) . \mathrm{NH}_{4} \mathrm{NO}_{3}, 1 \mathrm{~g}$; $\mathrm{KH}_{2} \mathrm{PO}_{4}$, $0.7 \mathrm{~g} ; \mathrm{K}_{2} \mathrm{HPO}_{4}, 0.7 \mathrm{~g} ; \mathrm{NaCl}, 0.005 \mathrm{~g} ; \mathrm{FeSO}_{4} \cdot \mathrm{H}_{2} \mathrm{O}, 0.002 \mathrm{~g}$; $\mathrm{ZnSO}_{4} \cdot 7 \mathrm{H}_{2} \mathrm{O}, 0.002 \mathrm{~g} ; \mathrm{MnSO}_{4} \cdot 4 \mathrm{H}_{2} \mathrm{O}, 0.001 \mathrm{~g}$; Biotin, 20 $\mathrm{mg}$; PVC, $1 \mathrm{~g}$; PH-7. By then the flask was anguished at any rate for 14 days in the shaker brooding focus (Neolab, India). Following fourteen days $1 \mathrm{~mL}$ of supernatant was moved into the comparable new medium. Reiterated on various occasions over a comparative methodology. In each repeated upgrade culture, the centralization of PVC in the medium ceaselessly expanded from 0.1 to 0.5 per cent. Visual assessment watched the advancement as an expansion in the turbidity of the lifestyle stock

\section{Screening of Polyvinyl Chloride Degrading Bacteria Strain}

A part of advancement culture was weakened satisfactorily with clean saline and spread on the supplement agar plates. Emerging was done at $30^{\circ} \mathrm{C}$ for $48 \mathrm{~h}$. Singular colonies shaped on supplement agar were picked and tried for their capacity to develop on a strong MSV medium containing emulsified PVC, where the medium was braced with supplement and with no enhancement, for example, $0.1 \%$ yeast extricate and $0.1 \%$ glucose. The strong MSV medium containing emulsified PVC was set up by altering the system recently utilized by Ishigaki et al. (2000). The agar plates were set up by dissolving $0.1 \mathrm{~g}$ of polyvinyl chloride in 25 $\mathrm{mL}$ of tetrahydrofuran. The arrangement was then added to liquid MSV agar medium at $50^{\circ} \mathrm{C}$ to $60^{\circ} \mathrm{C}$ with delicate shaking and plates were poured right away. The covers of the plate were kept part of the way opened for at any rate 30 min to permit total dissipation of dissolvable. The tops of the plates were then supplanted. Unadulterated societies of the PVC debasing microscopic organisms were gotten by rehashed sub-refined of the segregated provinces on a similar medium. The chosen detaches were allotted with codes, for instance, DS-A, DS-B etc., for additional examination.

The chosen segregates were portrayed utilizing Bergey's manual of determinative bacteriology. A part of advancement culture was weakened satisfactorily with clean saline and spread on the supplement agar plates. Hatching was done at $30^{\circ} \mathrm{C}$ for $48 \mathrm{~h}$. Singular provinces shaped on supplement agar were picked and tried for their capacity to develop on a strong MSV medium containing emulsified PVC, where the medium was braced with supplement and with no enhancement, for example, $0.1 \%$ yeast extricate and $0.1 \%$ glucose. The strong MSV medium containing emulsified PVC was set up by altering the system recently utilized by Ishigaki et al. (2000). The agar plates were set up by dissolving $0.1 \mathrm{~g}$ of polyvinyl chloride in $25 \mathrm{~mL}$ of tetrahydrofuran. The arrangement was then added to liquid MSV agar medium at $50^{\circ} \mathrm{C}$ to $60^{\circ} \mathrm{C}$ with delicate shaking and plates were poured right away. The covers of the plate were kept part of the way opened for at any rate $30 \mathrm{~min}$ to permit total dissipation of dissolvable. The tops of the plates were then supplanted. Unadulterated societies of the PVC debasing microscopic organisms were gotten by rehashed sub-refined of the segregated provinces on a similar medium. The selected isolates were allotted with codes, for instance, DS A, DS B, etc., for additional examination. The chosen segregates were portrayed utilizing Bergey's manual of determinative bacteriology. 


\section{RESULTS AND DISCUSSION}

\section{Identification, Isolation and Capability of Plastic Microorganisms Degrading from Soil}

This investigation manages the isolation, distinguishing proof, and capacity of plastic microorganisms degrading from the soil. Identification of isolated bacterial strains was done by Bergey's manual followed by plate morphology, physiological test and biochemical test (Table 1). During the biochemical examination, different sorts of changes are delivered by the microorganism. Through perceptible and minuscule investigations these bacterial strains were confined and portrayed. Polymer biodegradation was estimated in polymer and FTIR spectroscopy utilizing weight reduction. In this manner, microbial colonization term is a significant factor that impacts the period.

Table 1: Bacterial strain morphology by serial dilution method.

\begin{tabular}{|c|c|c|c|c|c|c|c|c|}
\hline \multicolumn{9}{|c|}{ Characteristics of the colony and morphological tests } \\
\hline \multicolumn{3}{|l|}{ Test } & \multicolumn{3}{|l|}{ Isolate 1} & \multicolumn{3}{|c|}{ Isolate 2} \\
\hline \multicolumn{3}{|l|}{ Margin } & \multicolumn{3}{|l|}{ Entire } & \multicolumn{3}{|c|}{ Rhizoid } \\
\hline \multicolumn{3}{|l|}{ Configuration } & \multicolumn{3}{|l|}{ Circular } & \multicolumn{3}{|c|}{ Circular } \\
\hline \multicolumn{3}{|l|}{ Surface } & \multicolumn{3}{|l|}{ Smooth } & \multicolumn{3}{|c|}{ Granular Shiny } \\
\hline \multicolumn{3}{|l|}{ Elevation } & \multicolumn{3}{|l|}{ Convex } & \multicolumn{3}{|c|}{ Slightly raised } \\
\hline \multicolumn{3}{|l|}{ Opacity } & \multicolumn{3}{|l|}{ Opaque } & \multicolumn{3}{|c|}{ Opaque } \\
\hline \multicolumn{3}{|l|}{ Pigment } & \multicolumn{3}{|c|}{ Creamish yellow } & \multicolumn{3}{|c|}{ White/Pale } \\
\hline \multicolumn{3}{|l|}{ Cell shape } & \multicolumn{3}{|l|}{ Rods } & \multicolumn{3}{|l|}{ Rods } \\
\hline Grams reaction & & & - & & & + & & \\
\hline Arrangement & & & Scattered & & & Short & & \\
\hline Size $(\mu \mathrm{m})$ & & & $3-4 \mathrm{um}$ & & & $0.8-1$ & & \\
\hline Motility & & & + & & & + & & \\
\hline Spore(s) & & & - & & & + & & \\
\hline B. Physiological test & & & & & & & & \\
\hline Growth at $\mathrm{pH}$ & & & Gr & $h$ at tempe & & & Growth & [\%] \\
\hline $\mathrm{pH}$ & Isolate 1 & Isolate 2 & temperature & Isolate 1 & Isolate 2 & $\mathrm{NaCl}$ & Isolate 1 & Isolate 2 \\
\hline pH 5 & - & - & $4^{\circ} \mathrm{C}$ & - & - & 2.0 & + & + \\
\hline pH 6 & + & + & $10^{\circ} \mathrm{C}$ & - & - & 4.0 & + & + \\
\hline pH 7 & + & + & $25^{\circ} \mathrm{C}$ & + & + & 6.0 & - & + \\
\hline pH 8 & + & + & $30^{\circ} \mathrm{C}$ & + & + & 8.0 & - & + \\
\hline pH 9 & + & + & $37^{\circ} \mathrm{C}$ & + & + & 10.0 & - & + \\
\hline & & & $42^{\circ} \mathrm{C}$ & + & + & 13.0 & - & + \\
\hline & & & $55^{\circ} \mathrm{C}$ & - & + & & & \\
\hline C. Biochemical tests & & & & & & & gar fermer & \\
\hline Tests & Isolate 1 & Isolate 2 & & & Tests & & Isolate 1 & Isolate 2 \\
\hline Voges Proskauer test & - & - & & & Trehalose & & & \\
\hline Indole test & - & - & & & Xylose & & & \\
\hline Methyl red test & - & + & & & Mannose & & & \\
\hline $\mathrm{H}_{2} \mathrm{~S}$ production & - & - & & & Sorbitol & & & \\
\hline Citrate utilization & - & - & & & Lactose & & & \\
\hline Gelatin hydrolysis & + & + & & & Galactose & & & \\
\hline $\begin{array}{l}\text { Production of Gas } \\
\text { from glucose }\end{array}$ & - & - & & & & & & \\
\hline Oxidase test & + & + & & & & & & \\
\hline Catalase test & + & + & & & & & & \\
\hline E. Probable identificati & $\mathrm{n}$ of isolates & & & & & & & \\
\hline Isolates & & & Identified iso & & & & & \\
\hline Isolate 1 & & & Bacillus sp. & & & & & \\
\hline Isolate 2 & & & Micrococcus & & & & & \\
\hline
\end{tabular}


For the isolation of polyvinyl chloride degrading bacteria, soil samples taken from several contaminated sites were used as a microbial source. PVC's potential Degrading microbial strains from enriched sources were first grown on nutrient agar, resulting in high cell density and big, cultivable colonies (Fig. 1), then the obtained culture named DS A and DS B were transferred into minimal agar medium plates enriched with PVC resin for the carbon source and incubate for 15 days at $30^{\circ} \mathrm{C}$ temperature (Fig. 2).

\section{PVC Film Degradation}

After 1.5 long stretches of brooding, the plaques were watched. During the trial, following fourteen days of hatching, microbial settlement began showing up from the film's edges and secured the whole film inside the 6th seven-day stretch of brooding. Anyway, it was impractical to do the test after that because of the parchedness of the way of life media. After the sixth seven-day stretch of hatching the photos of the biofilms were taken. (Fig. $3 \& 4$ ). Individual colonies were then examined to see whether they could grow on polyvinyl chloride (PVC) film in mineral salt agar media with and without replenishment (Fig. 5).

\section{Result of Plastic Samples Being Degraded by Bacteria}

The bacterial strains are disengaged and performed based on plainly visible and tiny assessment and biochemical tests with the capacity to debase. Bacterial secludes were visibly recognized by looking at state attributes, color, size shape,

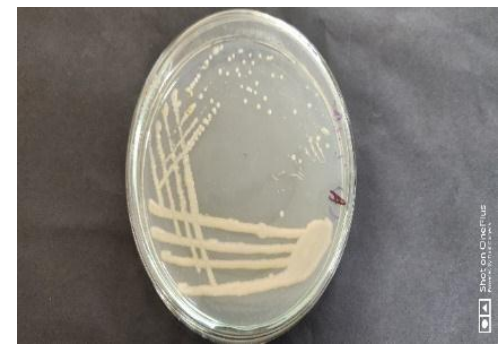

Fig. 1: Isolated culture colonies on the nutrient agar plate.

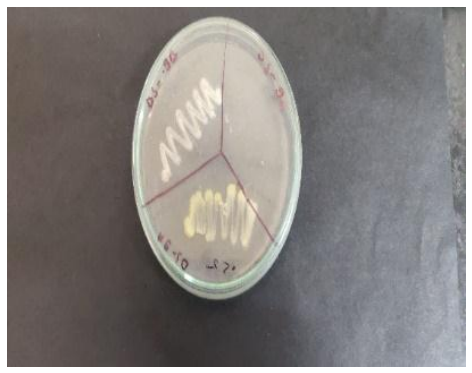

Fig. 2: Isolated colonies of strain DS A and DS B on MSM PVC agar plate (After 15 days of incubation). edge, and minuscule assessment including recoloring grams to examine the recoloring conduct, shape, and cell plan and granulation, just as spore recoloring, biochemical testing of motility. There was an aggregate of 2 cutoff points disengaged from the dirt dumped from the Gwalior City dumping zone. Recommendations 2 separate were cleaned to tilt to the going with test and screened for plastic contamination by anguishing under $37^{\circ} \mathrm{C}$ temperature conditions in a 130 rpm alarming incubation center shaker for half year. The bacteria explicitly got from the above biochemical tests are the PIBWIN (Probabilistic Bacterial Identification) software Bacillus and Micrococcus. Sullied Polyethylene Plastic Waste (Kathiresan 2003). Gage polyethylene plastic (beginning weight), wash with refined sterile water by then and sprinkle with 70 per cent liquor. Plastic is embedded aseptically into the $100 \mathrm{~mL}$ Erlenmeyer that contains as much as $50 \mathrm{~mL}$ of both NB and TSB media. The media had immunized as much as 2 circles for isolated bacteria. By at that point, struggled at room temperature in a hatching community shaker, with a perturbance of $130 \mathrm{rpm}$ for every month. Polyethylene plastic, conveyed for a colossal piece of a year, washed with refined sterile water and then washed with dried alcohol, evaluated by then (last weight). Picking the corruption level of polyethylene plastic by bacteria utilizing condition:

$$
\% \text { Degradation }=\frac{\text { Initial weight-Final weight }}{\text { Initial weight }} \times 100 \%
$$

To examine this, pre-assessed $1 \mathrm{~cm}$ wide circles arranged from polythene sacks were moved aseptically to a fixed carafe containing $50 \mathrm{~mL}$ of medium culture stock, self-rulingly immunized with different bacterial species. Control was kept up in a free creature medium, with plastic sheets. Two

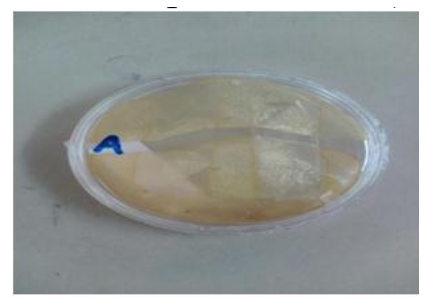

Fig. 3: Biofilm formed on PVC strip by strain A.

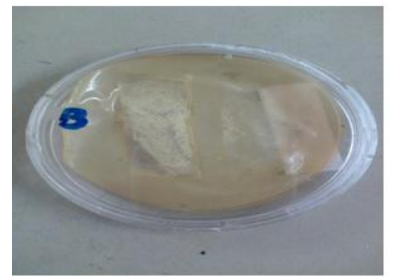

Fig. 4: Biofilm formed on PVC strip by strain B. 
carafes had been held up for every treatment and left in a shaker. Following a half year of shaking, the plastic circles were assembled, washed totally utilizing refined water, dried in shade and then weighed for conclusive weight. The weight reduction for the polythene pack was settled from the data accumulated. The attempted species incorporated the $\mathrm{Ba}$ cillus and the Micrococcus. Bacillus and Micrococcus were found in the half-year time period as being typically unique in degrading $12.7 \%$ of the bacteria and $8.4 \%$ liberated from PVC (Table 2) and graphical representation of \% degradation of PVC film by Bacillus and Micrococcus sp. (Fig. 6).

\section{FTIR Spectra of BOPP Film in Compost and Media, Before and After Degradation}

Fourier Transform Infrared Spectroscopy test was utilized to see the movement of new handy parties or changes in the

Table 2: Consequence of plastic samples being corrupted by bacteria.

\begin{tabular}{|lllll|}
\hline $\begin{array}{l}\text { Isolates } \\
\text { no. }\end{array}$ & $\begin{array}{l}\text { Bacteria } \\
\text { name }\end{array}$ & $\begin{array}{l}\text { Initial } \\
\text { wt }[\mathrm{g}]\end{array}$ & $\begin{array}{l}\text { Final } \\
\text { wt }[\mathrm{g}]\end{array}$ & $\begin{array}{l}\text { Weight Loss in per- } \\
\text { centage after 6 month }\end{array}$ \\
\hline 1 & Bacillus & 1.0 & 0.873 & 12.7 \\
2 & $\begin{array}{l}\text { Micrococ- } \\
\text { cus }\end{array}$ & 1.0 & 0.916 & 8.4 \\
& Control & 1.0 & 0.00 & 00 \\
\hline
\end{tabular}

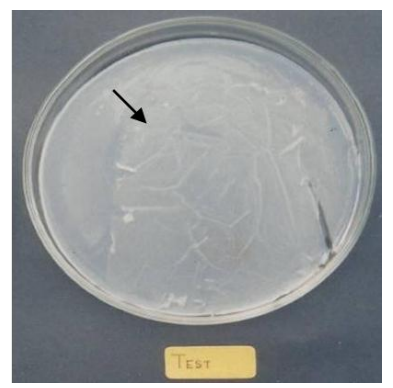

Fig. 5: Growth of strain B on polyvinyl chloride film placed on mineral salt media. current utilitarian ties (Milstein et al. 1994); FTIR Spectra Plastic Material (Figs. 7, 8, and 9) show contamination of the plastic material FTIR spectra in the wake of being segregated from bacterial strain. The covering spectra inside the expanded structure, which clearly shows the movements watched, are likewise open to a relationship.

Figs. 7 and 9 show plastic corruption in made media, utilizing bacteria. Gathered and included soil-hawked plastic strips to the organized medium containing bacterial species Bacillus and Micrococcus which are viewed as less plastic degrading as an extra decomposer. In the medium, weight mishaps of polymer strips could be seen as a marker of biodegradation in landfills, or standard living space. Microorganisms have attacked the Polymer strips in the soil.

\section{DISCUSSION}

The present study deals with the Isolation and characterization of Polyvinyl chloride degrading bacteria from polluted sites. Different types of changes are observed by the isolates during morphological and chemical analysis. Another area examined has been the biodegradation of plastic by the liquid culture method. It is clear that the polymers to some extent can be degraded in the appropriate environment in the right concentration. Here, it was concluded that Bacillus show a

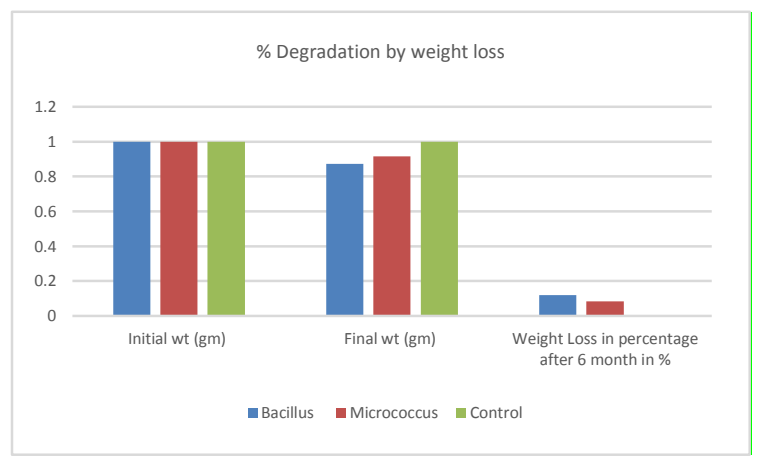

Fig. 6: Graph of PVC degradation after six months.

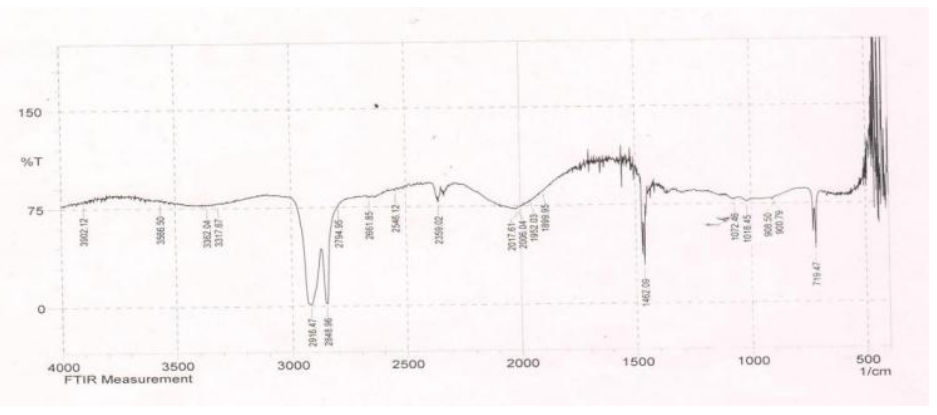

Fig. 7: FTIR plastic spectra before decay. 


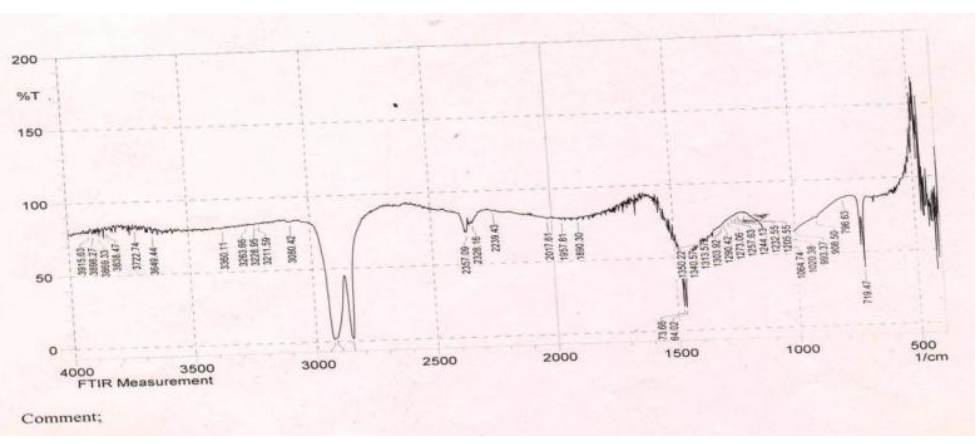

Fig. 8: FTIR spectra of plastics after Bacillus degradation.

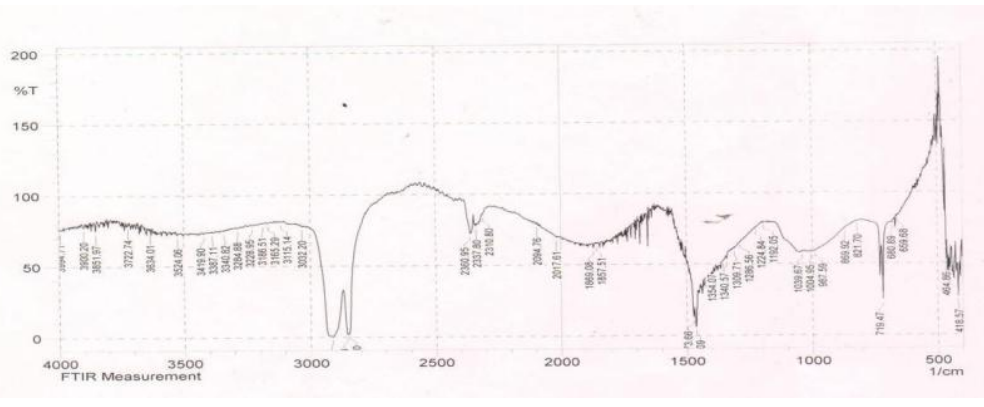

Fig. 9: FTIR spectra of plastics after Micrococcus degradation.

greater potential of degradation than Micrococcus. As the PVC was prepared in the laboratory so there might be some error during the preparation. Microbial degradation of a solid polymer like PVC requires the formation of biofilm which has also been tested in this study. The microbes utilize these insoluble substrates by enzymatic activities (chitinase and glucanase assay). The development of such biofilms on the surface of synthetic waste can prove to be a very efficient method for the degradation of these polymers in vitro. The results obtained in the study showed that the isolated strain survived on the plastic film surface. Biofilms were observed on the surface of the PVC strips, it can be concluded that the bacterial strains degraded the plastic and also gives a positive intimation that the isolate can be used as a potent biodegrading agent for plastic waste material. The large scale application of this method may prove as environmentally profitable research.

\section{CONCLUSION}

In conclusion, the microbial strains from the collected sample were successfully isolated with the potential to degrade synthetic polymers like polyvinyl chloride and polyethylene. Bacillus strain was found to possess the plastic degrading potential and its efficiency was maximum compared to other bacteria. These discoveries have significant application in taking care of the issue of plastic waste through bioremediation, where it is conceivable to consolidate and apply the present day approach produced for remediation with these living beings. Considering the synergism between these microorganisms will give knowledge into future endeavors to biodegrade those materials. In spite of screening downsized living animals in the earth, with inescapable execution, the unit of little scope marine living things, oil waste, and polymer dump site could make new unexplored strains. The microorganisms can be picked up and utilized as a superbug to decay the unmanageable plastics. If there should be an occurrence of utilizing current characteristic structure mechanical social affairs to outline the qualities and conclude that are answerable for the game plan of produced corruption escalates. It will be helpful in the removal of these hazardous substances from the environment that leads to the accomplishment of a sustainable and plastic-free environment.

\section{REFERENCES}

Arutchelvi, J., Sudhakar, M., Arkatkar, A., Doble, M., Bhaduri, S. and Uppara, P.V. 2008 Biodegradation of polyethylene and polypropylene. Indian J. Biotechnol., 7: 9-22.

Cregut, M., Bedas, M., Durand, M.J. and Thouand, G. 2013. New insights into polyurethane biodegradation and realistic prospects for the development of a sustainable waste recycling process. Biotechnol. Adv., 31 : 1634-1647. doi: 10.1016/j.biotechadv.2013.08.011 
Garcia, J.M. and Robertson, M.L. 2017. The future of plastics recycling. Science, 358: 870-872.

Geyer, R., Jambeck, J. and Law, K.L. 2017. Production, use, and the fate of all plastics ever made. Sci. Adv., 3: e1700782. doi: 10.1126/sciadv. 1700782

Ho, B.T., Roberts, T.K. and Lucas, S. 2018. An overview on biodegradation of polystyrene and modified polystyrene: The microbial approach. Crit. Rev. Biotechnol., 38: 308-320. doi: 10.1080/07388551.2017.1355293

Ishigaki, T., Kawagoshi Y., Ike, M. and Fujita, M. 2000. Abundance of polymer degrading microorganisms in sea-based soil waste landfill sites. Joun. Basic. Microbiol., 90: 400-405

Kathiresan, K. 2003. Polythene and plastic-degrading microbes in an Indian mangrove soil. Rev. Biologica. Tropica. 51: 629-633

Kawai, F., Kawabata, T. and Oda, M. 2019. Current knowledge on enzymatic PET degradation and its possible application to waste stream management and other fields. Appl. Microbiol. Biotechnol., 103: 4253-4268. doi: 10.1007/s00253- 019-09717-y

Magnin, A., Hoornaert, L., Pollet, E., Laurichesse, S., Phalip, V. and Avérous, L. 2019. Isolation and characterization of different promising fungi for biological waste management of polyurethanes. Microb. Biotechnol., 12: 544-555. doi: 10.1111/1751-7915.13346

Milstein O., Gersonde R., Huttermann A., Frund R., Feine H.J., Ludermann. D.H., Chen. J.M. and Meister J. J. 1994. Infrared and nuclear magnetic Resonance evidence of degradation in thermoplastic based on forest products. Joun. of Environ. Polymer Degradat., 2: 137-15.

Patil R. and Bagde S.U. 2012. Isolation of Polyvinyl chloride degrading bacterial strains from environmental samples using enrichment culture technique. African Joun. of Biotechnol.,11(13): 7947-7956
Peng, R.T., Xia, M.L., Ru, J.K., Huo, Y.X. and Yang, Y. 2018. Microbial degradation of polyurethane plastics. Chin. J. Biotechnol., 34: 1398-1409.

Rahimi, A. and García, J.M. 2017. Chemical recycling of waste plastics for new materials production. Nat. Rev. Chem., 1: 0046.

Restrepo-Flórez, J., Bassi, A. and Thompson, M.R. 2014. Microbial degradation and deterioration of polyethylene: A review. Int. Biodeter. Biodegr., 88, 83-90. doi: 10.1016/j.ibiod.2013.12.014

Sharma, J., Gurung, T., Upadhyay, A., Nandy, K., Agnihotri, P. and Mitra, A. K. 2015. Isolation and characterization of plastic degrading bacteria from soil collected from the dumping grounds of an industrial area. Int. J. Adv. Innov. Res., 3: 2278-7844.

Shristi Kumar, K., Hatha, A.A.M. and Christi, K.S. 2007. Diversity and effectiveness of tropical mangrove soil microflora on the degradation of polythene carry bags. Int. J. Trop. Biol., 55: 777-786.

Spear, L.B., Ainley, D.G. and Ribic, C.A. 1995. Incidence of plastic in seabirds from the tropical Pacific 1984-91: Relation with the distribution of species, sex, age, season, year, and body weight. Mar. Environ. Res., 40: 123-141.

Tomita, K., Nakajima, T., Kikuchi, Y. and Miwa, N. 2004. Degradation of poly (L-lactic acid) by a newly isolated thermophile. Polym. Degrad. Stab., 84: 433-438.

Wei, R. and Zimmermann, W. 2017a. Biocatalysis as a green route for recycling the recalcitrant plastic polyethylene terephthalate. Microb. Biotechnol., 10: 1302-1307. doi: 10.1111/1751-7915.12714

Wei, R. and Zimmermann, W. 2017b. Microbial enzymes for the recycling of recalcitrant petroleum-based plastics: How far are we? Microb. Biotechnol., 10: 1308-1322. doi: 10.1111/1751-7915.12710 